\title{
Biopsias del Endometrio en Estudios de Esterilidad
}

\author{
Prof. Hernando Latorre L. \\ Jefe de Servicio de Anatomía Patológica. Hospital de San José.
}

Del material que preparamos para hacer la demostración de preparaciones histológicas de endometrio, durante el desarrollo de la Primera Convención de (inccologia y Obstetricia y como contribución al trabajo presentado por el perconal cientifico de la Sección de Esterilidad del Hospital de San José, extract.amos algunos de los casos, para hacer la presente publicación.

Corresponden todos ellos a biopsias de rutina, tomadas casi en su totalidad durante el primer dia de la menstruación o por lo menos, si tal no es en realidad el caso, en los primeros estadios de iniciada una hemorragia uterina.

Los datos principales que se pueden obtener con tales estudios se refieren a la existencia o no de postura ovular según que se encuentre o no la evidencia de una fase secretora, exceptuando los casos en que dicha imagen corresponda it una lutcinización anormal de estructuras ovaricas, a presencia de quistes o We cuerpos amarillos persistentes a a lis acción hormonal de ciertos tumores. In ededes ellos, el clinico podrá interpretar la imagen histologica de acuerdo con demas sintomas y signos que presente la conferma al examen y correlacionar - 11.1 mente con las otras investigaciones que se practiquen, como la temperatu 1.t basal, el diagnóstico citohormonal en secreciones vaginales, dosificación de pergnandiol o la persistencia de dicha imagen histologica en otras épocas del cich, ete. Igualmente podriamos decir de los trastornos de receptibilidad uteina, de metrosis de receptibilidad, evidenciadas por la discordancia de los da(10) suministrados por la biepsia endometrial y las otras pruebas funcionales, pué sólo en ciertos casos de origen neurovegetativo el endometrio puede perm.necer normal. El estudio del endometrio ensena también sobre la intensidad it. la acción estrogénica, según su respuesta normal, hiperplásica o hipoplásica ibre la respuesta a la accion progesteronal observando el grado de transfor the ion secretora; por último sobre la eventualidad de lesiones endometriales, cme ellas la tuberculosis que en la mayoria de los varios casos que hemos ob wado no se sospectó clinicamente o de otros procesos inflamatorios, como en uno que presentamos adelante, por retencion de tejido decidual correspondiente a un embarazo tubirico antiguo que habia pasado inadvertido. 


\section{MIPOESTROGENISMO)}

Endometrio atrofico. - Biopsia tomada el primer día de hemorragia. Insu liciencia estrogénica.. Rl epitclio superficial es bajo con muy escaso citoplasma. I estroma muestra sus celulas muy pequeñas, algunos vasos capilares, hemorra. i.s sub epitetial y locos arisludes mas profundos. Hay escasos tubos glandulares

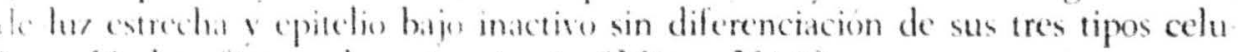
ace No h.s liguran de carieguinesis. (Micro, No2).

Endometrio atrofico. - Insuficiencia estrogénica. Falta de receptibilidad a atamiento progesteronal intenso, para metrorragin. Enferma hipotiroidiana, besil. Esterilidad primaria.

En este caso es de anotar que la bićpsia fue tomada después de varios días ge metrorragia la cual habia sido tratada sin resultado favorable con hormona ténici. El endometrio no muestra respuesta secretora por falta de receptibiHad (hipostrogenismo). Hay epitelio superficial bajo, estroma flojo de células quenas con escasos vasos capilares y muy pocos tubos glandulares de luz esfrceha y epitclio con citoplasma mal definido, poco aparente y núcleos muy pe faenos que apurecen a veces en varias filas pero sin signos de actividad (Mi (1) 13$)$.

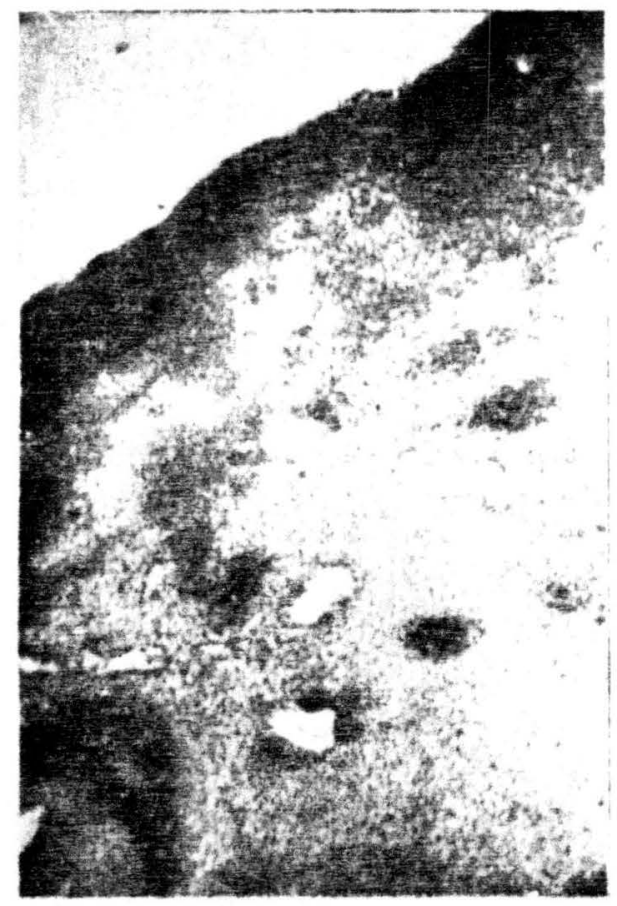

MICRO No 2

Primer día de hemorragia. Endometrio atrófico. Aparece ef estroma de chlulas pequehas con hemorragla $y$ tubos eptteinates inaetivos. 


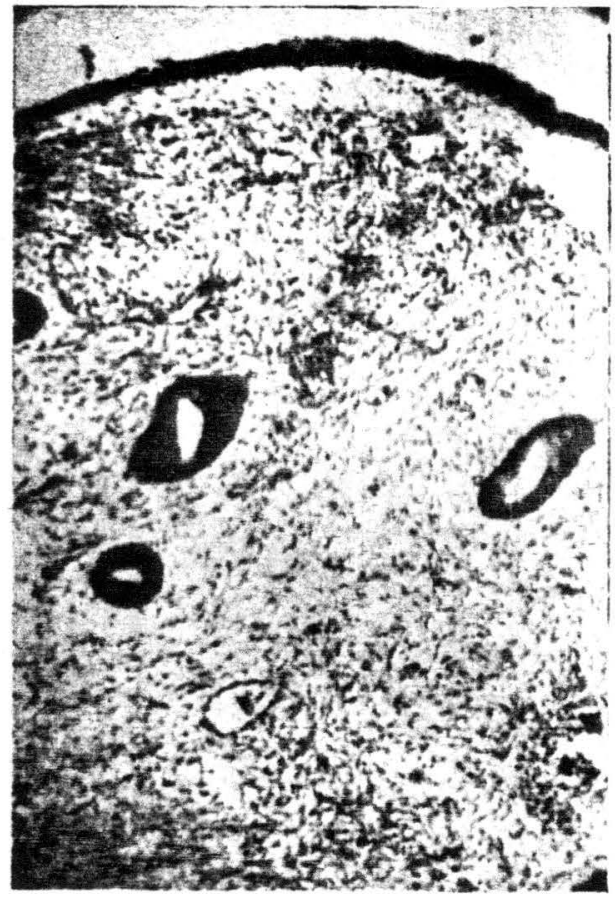

MICRO NQ 3

Endometrio atrófico. Entre el estroma flojo hay algunos tubos glandulares de luz estrecha, regular, con epitelio inactivo.

MICRO Ne 4

Primer dia de hemorragla. H.G.K. Se encuentran Elándulas quisticas con epitelio bajo y núcleos en varias filas. Hay figuras de carioquinexis.

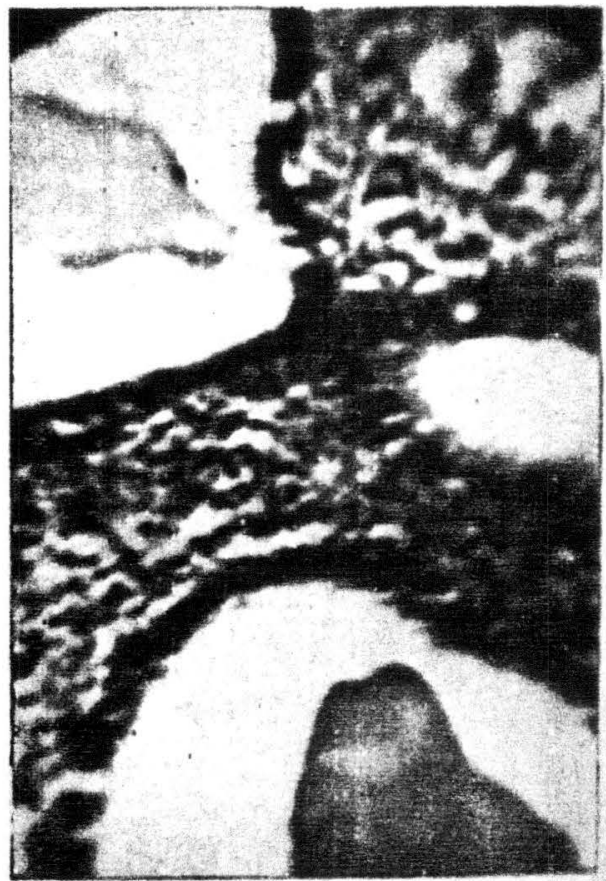




\section{HIPLRESTROG,INISMO}

A este grupe corresponden los cause de hiperfoliculinea absoluta o relativa. por estimule importante en corte tiempo, estimule debil persistente o a ende metrios anomalmente sensibles a l. homona motrosis de recoptibilidad). Los

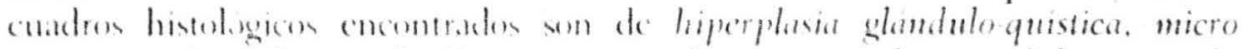

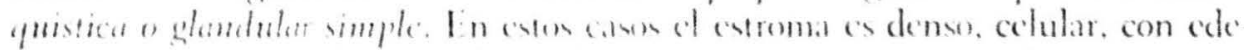
ma. dilatacion vascular, trombers, hemomigin, necrosis, focos leucocitarios y abundantes tuber glandulares yuivious (queso suizo) o microquisticos de epi telie cilindrico o cubico con nucleos en varias filas y figuras frecuentes de carioquinesis tanto en las celulas del estroma com en las epiteliales. En la forma glandular simple las abundantes glandulas que muestran desorganización e inva ginaciones, son de calibre mas pequeño y el epitelio alto, pseudo-estratificado. En las formas de hiperplasia atipica descritas por Novak hay anaplasia y mas irregularidad dando imágenes de semejanza neoplásica. (Micro. No 4).

\section{HIPERESTROG VE VISMO RELATIVO}

Hiperplasias mixtas. - En cases de hiperestrogenisme relativo se combina una cierta accion progesteronal sea por la coolucion concomitante de un C.A. con folicules persistentes a quistion, por luteinisacion de quistes foliculares o atresicos o lo que Pundel hallo mas frecuentemente como fueron cuerpos amari Hos quistion y homorrágios. Ia imagen hisologica de estos condometrios puede presentar una mexta de glandulas en fase secretora y otras en hiperplasia foli culinica o aun fenimenos de secrecion demostrades per vacuolizacion citoplas mica en glandulas quisticas, por ondulacion de la lus cosinofilia det epitelio

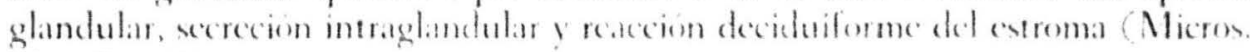
Vos. 5 y 6 ).

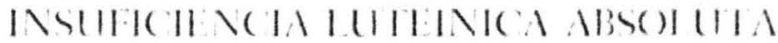

Es perfectamente consede que la menstruacion no esta en relacion direct. con la pestura oveular y que enta prede no efectuarse en cictes regulares indicades por la aparicion pertodica de la hemorragia uterinat as la anowalacion se traduce por un ciclo aluteal con la comsiguiente ausencia de la fase secretora endometrial. Los cuadros histologios an tales cases solamente demestran la intensidad del estimulo estrogénico por el grado de desarrollo de lat mocose que puede ir desde

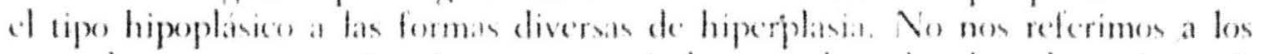

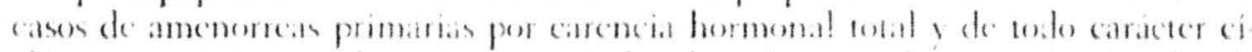
dien, consecutian a alteraciones genitales de aplasios o de agenesiats lis de ad

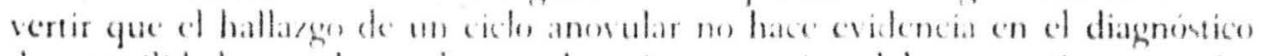
de esterilidad, por lo cual en takes circumsancias deben practicarse varios exámenes. 


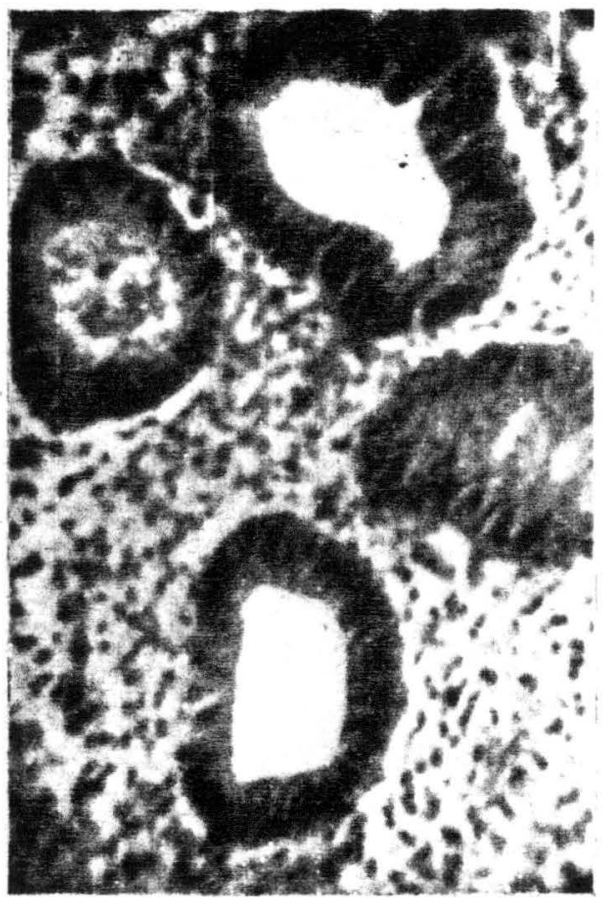

Micko No 5

Primer dia de hemorragia. Hiperplasia mixta. Parte estrogeni. ca. Tubos glandulares de luz re gular y epitrlio alto. pseudoestratifieado, con pestanas. Figuras de carioguinesis.

\section{MICkO Ne 6}

Hiperplasia mixta. Horción se. cretora. El mismo caso anterior, muestra glándulas de luy ondu. lada, y epltelio de citoplasma va. cuolado y núcieo basal.

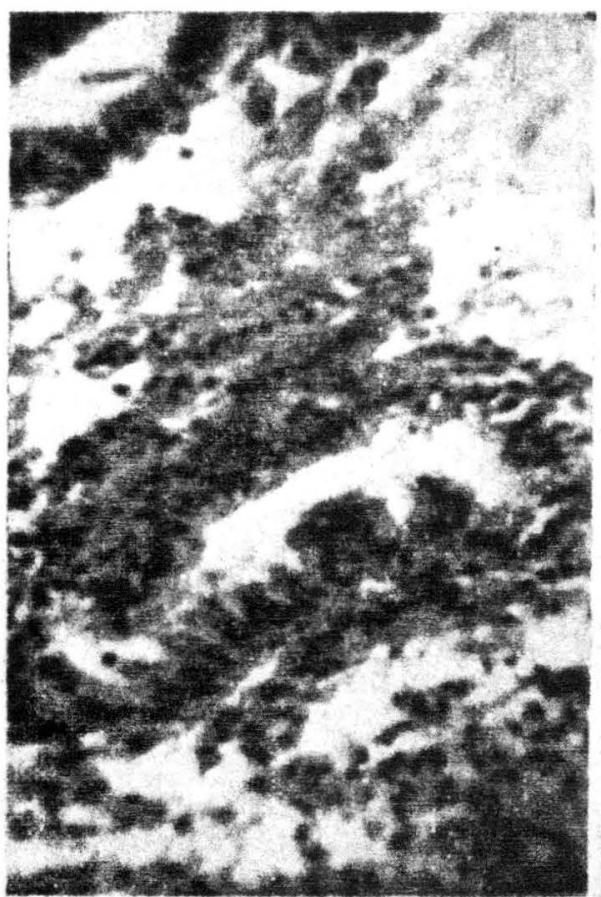


hemorragia, hay en ellos glándulas que muestran poca evidencia de secreción y en otras, de luz regular y epitelio bajo, de límites apicales netos y núcleos alargados con pseudoestratificación sin evidencia de hiperplasia. (Micro No 8).

\section{INSUIFICIENCIA LUTEINICA PARCIAI}

En la mavora de los casos la insuliciencia lutemica parcial se manifiesta por produccion insuficiente de luteina por un cuerpo amarillo sin que el endo metrio pueda llegar al estado progestativo normal: habra fecundacion pero la preparacion deficiente de la mucosi no permite al huevo su nidacion normal.

Las imágenes histologicas varian en relacion con el grado de la deficiencia y se refieren especialmente al cambie secretor poco neto de las glándulas, a escasa diferenciación de las arteriolas espirales lo mismo que a los caracteres del estroma. En éste, no se encuentra la reacción deciduiforme, no aparecen arteriolas espirales hacia la superficie y las glándulas sin la estructura en "dientes de sierra" normal, con poco citplasma escasamente vacuolado y con material de secreción poco aparente. Se observan imágenes que normalmente correspon derían a épocas anteriores del ciclo que como la presencia de vacuola glicogé nica infranuclear, que aunque puede corresponder solamente a una accion estrogénica acentuada, se acompaña aqui de otros signos que evidencia de ma nera mas neta alguna reacción secretora. Generalmente se considera que la fase luténica tiene una duración más o menos constante, sin embargo puede estar acortada con alargamiento de la fase foliculínica y por consiguiente disminuirse el tiempo para efectuar la reacción secretora completa.

Biópsia de endometrio tomada el primer dia del ciclo. Secrecién incipiente. En los cortes histologicos no se encuentra diferenciacion entre las capas fun cionantes. El estroma es denso, de células fusiforme con escaso citoplasma y en general agrupadas en fasicules, se encucntran grupen de arteriolas espirales de pared gruesi, hemorragia intersticial e infiltracion leucocitaria. Excepcional. mente se oberva epitelio superficial en cambio hay varias zonas de basal con escaso miometrio. Las glandulas en regular cantidad presentan calibre amplio, circular o ligeramente ondulado; el epitelio es columnar alto, de citoplasma va cuolado y nucleos redondos basales o centrales con vacuola infranuclear ( $\mathrm{Mi}$. cro $N 99$ ).

En otro caso tomado también en el primer dia de la regla y en donde se anotan hipermenorreas e hipotiroidismo se encuentra lo siguiente en las lámi nas histológicas: el endomctrio está bastante bien conservado, en pocas partes falta el epitelio superficial que es columnar alto; el estroma muestra edema, focos pequenos de hemorragia y discreta presencia de leucocitos, en sus células hay poca evidencia de reacción deciduiforme; hay bazos sanguíneos rotos y grupos de arteriolas espirales en la zona superficial. Las glandulas son abun dantes, de calibre amplio, de luz ligeramente ondulada y pocas las muestan bien festoneada; las células epiteliales son altas, con citoplasma finamente va cuolado y los núcleos redondos basales o centrales (Micro No 10). 


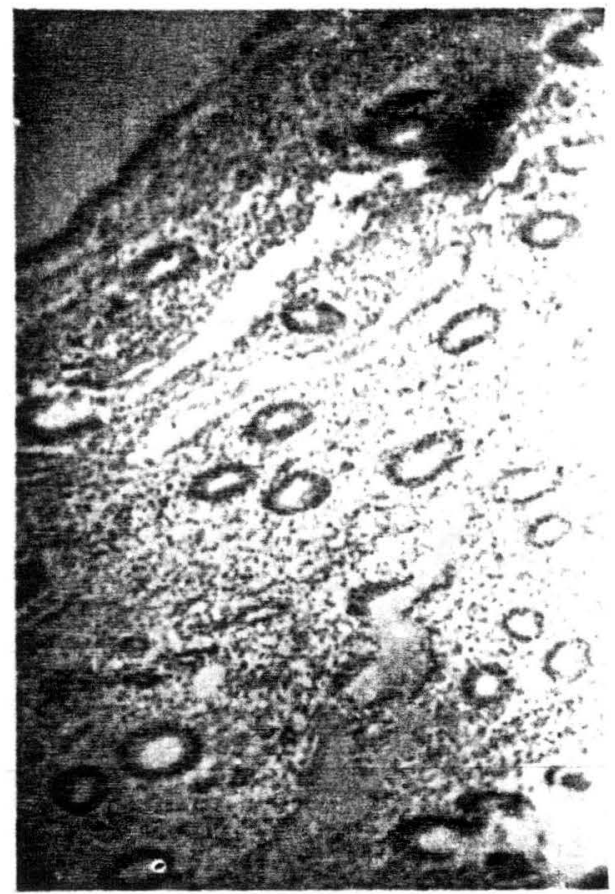

MICRO No

Ciclo anovular. Biópsia tomada el primer dia de himorragia. Muestra el estroma He células pequeñas y tubos glañulares de luz regular con sus células bajas y núcleos en varias filas

MICRO Ne 8

Primer dia del ciclo. Maduración irregular. Se observan glandulas con agotamiento secretor y otran de tipo estrogenico.

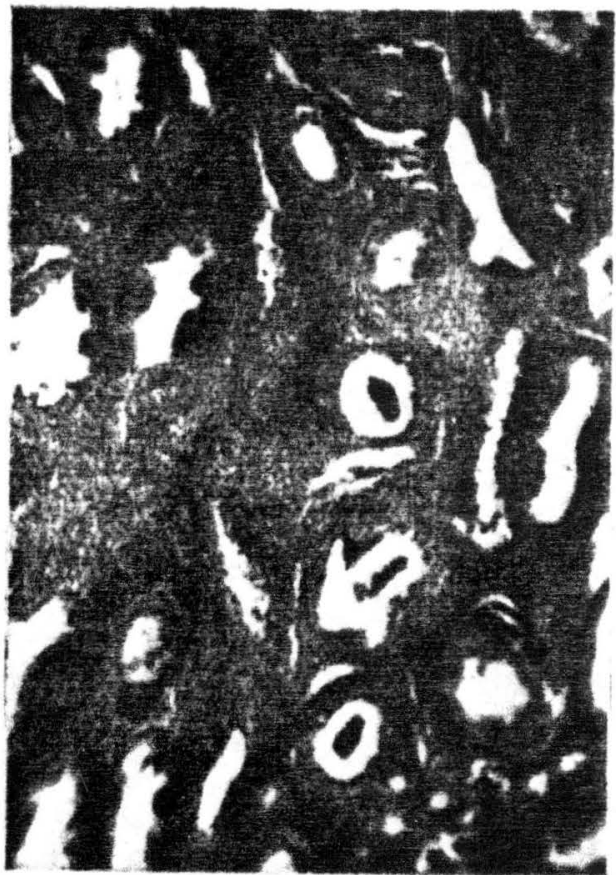




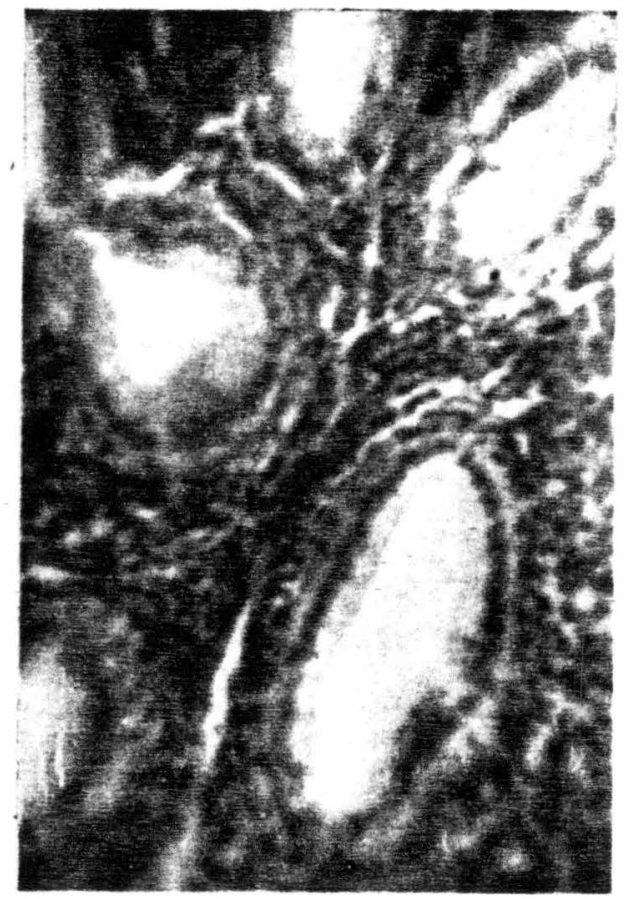

MICRO Ne' 9

Primer día del ciclo. Secreción incipiente. Glándulas de luz amplia. epitelio alto con núcleos centrales y vacuota infranuclear.

\section{MICRO NO 10}

Primer dia del riclo. Secreción insuficiente, Giandulas do luz ampla, regular, con escaso citoplasma y nucleos basales.

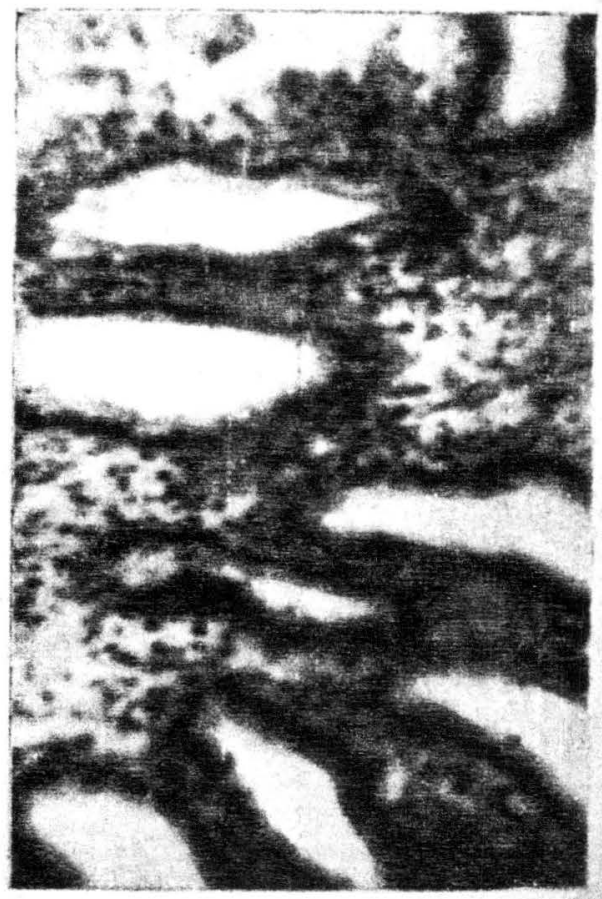




\section{IIIPLRIOIIINISIO)}

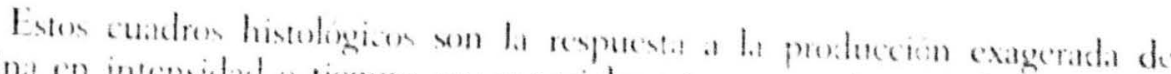

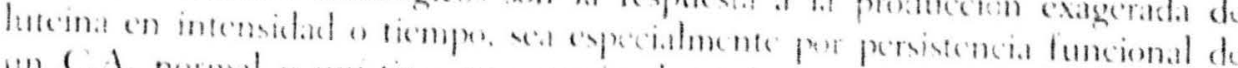

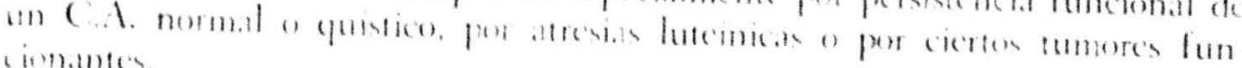
ciomintes

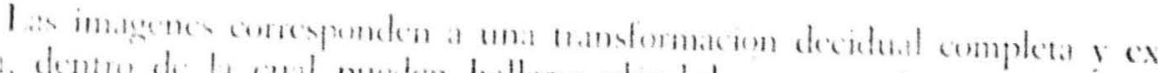

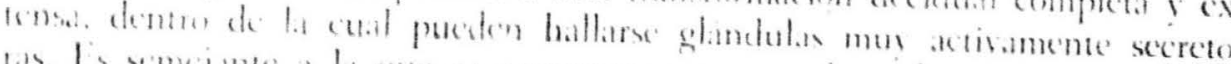

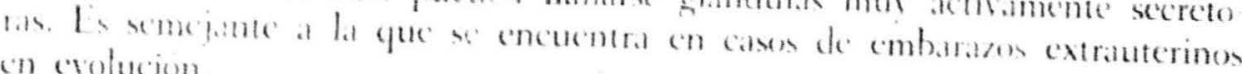
(in evolucion.

\section{PROCESOS INHLAMATORIOS}

La T.B.C. es entre los procesos inflamatorios ol que mas frecuentement homos encontrate en las biopsias para estudios de esterilidad, siendo de ano far que en muchos de cotos casses no se hubiesen presentado trastomos clínico. aparentes que permiticran hacer ef diagnestice presio al hallazgo histologion. En todos los estudion de estes endemetries hemes visto eridencia de accion hor monal ovarian. pere de tipe e intensidad sariables. En unos. el procese granu lematese aparece en endometris tepicamente menstrual, a decit, con los signos de la reacien secretora completa. Otros endometrios son de tipe aluteal con respuesta estrogenica mas o menes marcadar y quizat, he que ha sido más fre cuente, les gramulomas se encuentan losalizades en areas con perdida de la re ceptibilidad a la luteina. La imagen histolegica se caracteriat por la presencia de mbercutes an sue colulas epitelisides y gigantes de langhan de morfo

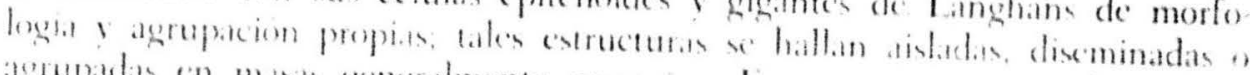

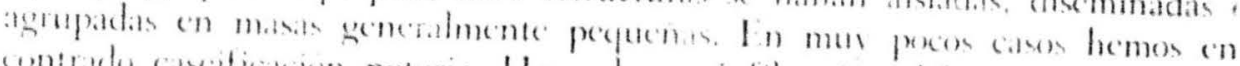

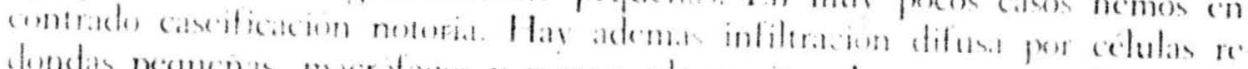

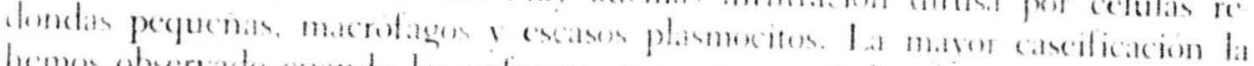
hemos obsersade comede las cotermas presenten perodo de amenorrea, alcan

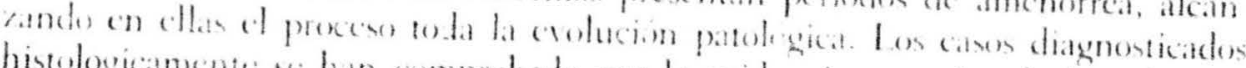

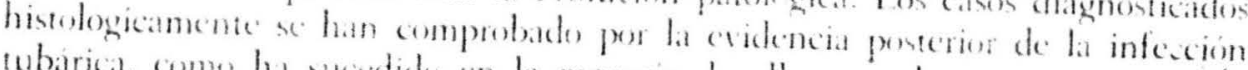
tubarica, como ha sucedide en la mayoria de elles, por la presencia eventual

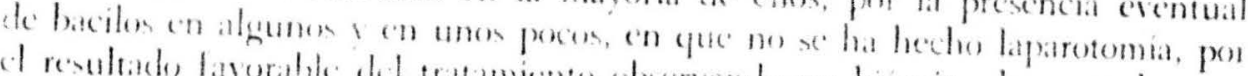

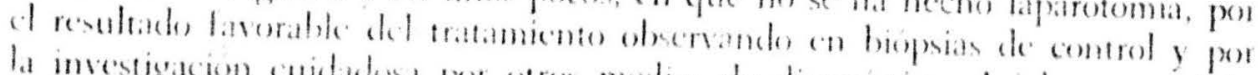

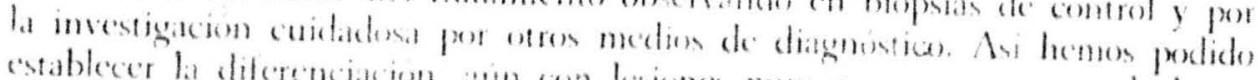

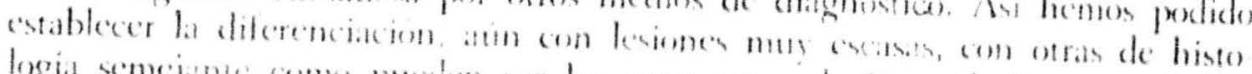

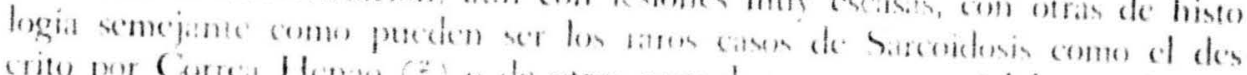

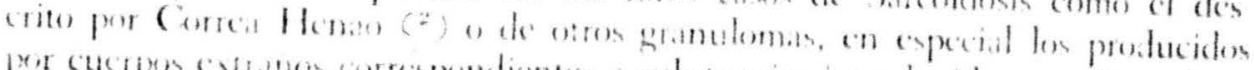

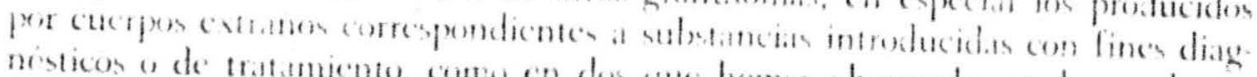

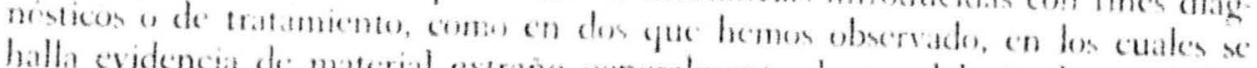
halla evidencia de material extrano generalmente dentro del copplasma de las celulas gigantes uno de cotos cosos fue publicado por nosetros ("). 
Entre los procesos inflamatorios anotamos tambien la posibilidad de endometritis crónicas producidas por la retención de estructuras de embarazo cuando se han presentado abortos no diagnosticados o como en el ejemplo que adelante insertamos, de un embarazo tubárico que fue operado dias despues de haber en contrado en el examen histologico del endometrio, un fragmento muy pequeño de decidua parcialmente necrosidat.

Tuberculesis endenetrial. - Biopsia de endenetrio tomadia en el primes dia del ciclo. Se encuentran partes con epitelio superficial alto, estroma de ef

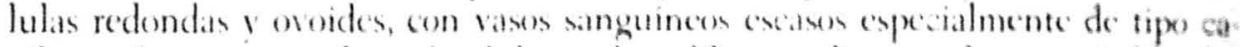
pilar y frecuentes tubos glandulares de calibre medio, regular y epitelio alto con varias filas nucleares, correspondiente a un ciclo anovular. Hay granulomas constituidos por celulas gigantes del tipo Langhns rodeadas por células epite lioides y linfocitarias; se observa además infiltracion inflamatoria difusa por cé lulas redondas y polimorfonucleares en el estroma y en la luz glandular (Mi. cros Nos. 11 y 12 ).

Endometritis cronica por retención decidual. - Bicsia del endometrio tomada el primer dia de la regla, en estudio para esterilidad.

En los cortes histologicos no se encuentra la imagen de fase menstrual. E! estroma está constituido por celulas pequenas redondas $y$ alargadas, sin arteriolas espirales, con hemorragia e infiltracion leucocitaria y edema. El epitelio superficial es alto con varias filas nucleares. Las glandulas son frecuentes, de diferentes calibres, la mayoria de luz regular, formadas por epitclio cilindrico de límites apicales netos, nuicleos alargados, tenidos, a veces situados en varias filas; en algu. nos tubos el núcleo es central con vacuola glicogenica subyacente y hay glándu.

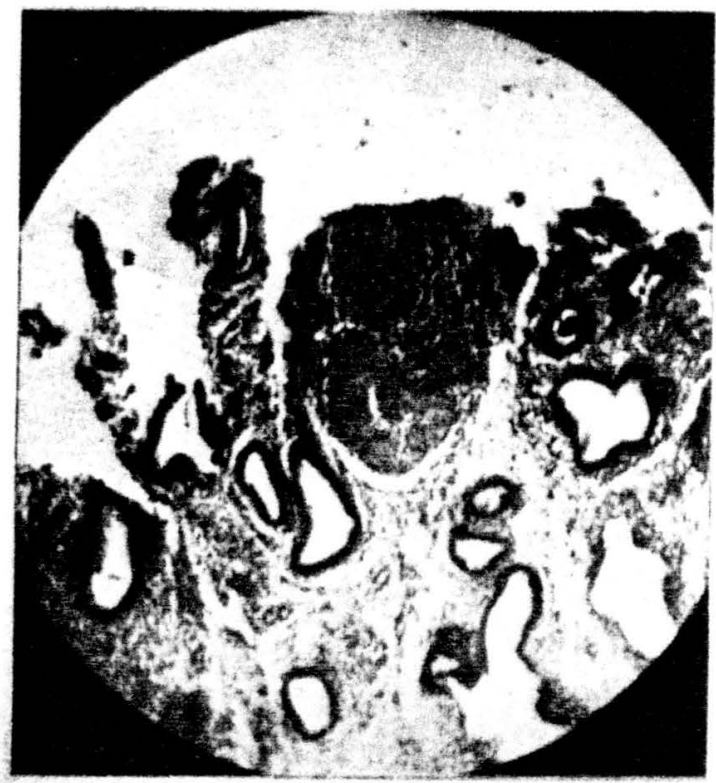

MICRO N"

Primer dia del eiclo (anovular). se rncuentran foliculos T.h.C. (pequeno atumento). 


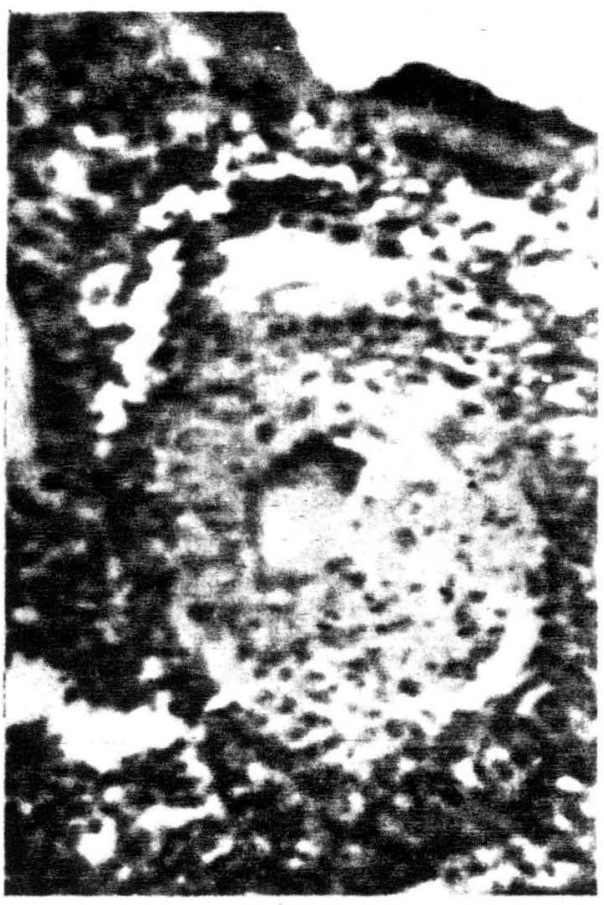

MICRO No 1 ?

El mismo caso anterior. In fo-

liculo tuberculose co: arand?

aumento.

MI(R) No is

Con grande aumento se observa

el fractento de decidua

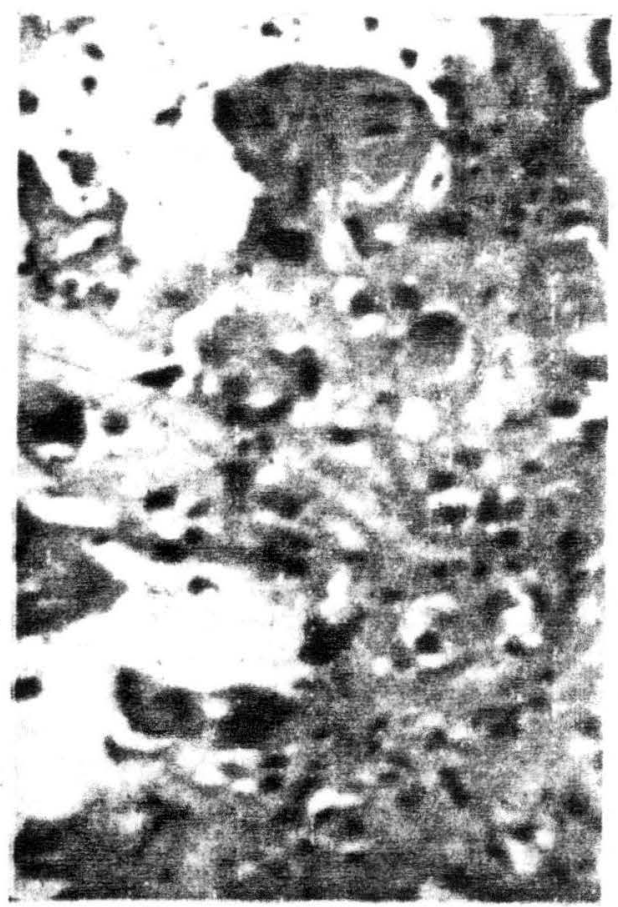


las de luz ligeramente ondulada con células de citoplasma vacuolado y núcleo basal. Se observan por consiguiente indicios de reacción secretora insuficiente y áreas con falta de receptibilidad luteínica. Nos llamó la atención la presencia de área necrosada en la cual sé encuentran restos de células grandes de núcleo hipercromático que interpretamos como elementos deciduales alterados, lo cual nos fue confirmado luégo por el ginecólogo al referimos que la enferma, des pués de la toma de la biopsia, habia presentado una sintomatologia anexial que indico la necesidad de una intervencion quirurgica, habiendese encontrado un embarazo tubárico antiguo (Micro No 13).

Resumen. - Se hace la descripción histológica de biopsias endometrales en estudios para la esterilidad, en relación con la investigación de postura ovu lar, de las alteraciones por desequilibrio hormonal o de receptibilidad y por pro cesos inflamatorios.

\section{B I B L I O G R A F I A :}

1. -Boyd, W.: "A Textbook of Pathology". Lea \& Febiger. Ph. 1953.

2. - Correa Henao, A.: "Sarcoidosis". Antioquia Médica. Vol. 1; 1950, 243-257

3. - Cowdry, E. V.: "A Textbook of Histology". Lea \& Febiger. Ph. 1950.

4.-Faulkner, R. L.: "Essentials of Obstetrical and Gynecological". Pathology Mos by Co. St. Louis $1949,2^{\text {a }}$ Ed.

5. -Latorre L., H.: "Salpingitis granulomatosa bilateral por cuerpo extraño". Rep de Med. y Cirug. Vol. V. 1950, 74-79.

6.-Novak, E.: "Gynecological and Obstetrical Pathology". Saunders Co. Ph. 1946

7.--Papanicolaou, G. N.; Traut, H. F.; Marchetti, A. A.: "The Epithelia of Wornan's Reproductive Organs". The Commonwealth Fund. N. Y., 1948.

8. -Fundel, J. P.: "Les Frottis vaginaux et Cervicaus". Masson \& Cie., Paris, $19 \$ 0$

9.-Traut, H. F.; Kuder, A.: "Irregular shelding and irregular ripening of the en: dometrium". Surg. Gyn. \& Obst., 1936, 61, 145. 